\title{
SPATIAL PATTERN AND ECOLOGICAL PROCESS IN THE COFFEE AGROFORESTRY SYSTEM
}

\author{
Ivette Perfecto ${ }^{1,3}$ And John Vandermeer ${ }^{1,2}$ \\ ${ }^{1}$ School of Natural Resources and Environment, University of Michigan, Ann Arbor, Michigan 48109 USA \\ ${ }^{2}$ Department of Ecology and Evolutionary Biology, University of Michigan, Ann Arbor, Michigan 48109 USA
}

\begin{abstract}
The coffee agroforestry system provides an ideal platform for the study of spatial ecology. The uniform pattern of the coffee plants and shade trees allows for the study of pattern generation through intrinsic biological forces rather than extrinsic habitat patchiness. Detailed studies, focusing on a key mutualism between an ant (Azteca instabilis) and a scale insect (Coccus viridis), conducted in a 45-ha plot in a coffee agroforestry system have provided insights into (1) the quantitative evaluation of spatial pattern of the scale insect Coccus viridis on coffee bushes, (2) the mechanisms for the generation of patterns through the combination of local satellite ant nest formation and regional control from natural enemies, and (3) the consequences of the spatial pattern for the stability of predator-prey (hostparasitoid) systems, for a key coccinelid beetle preying on the scale insects and a phorid fly parasitoid parasitizing the ant.
\end{abstract}

Key words: Azia orbigera; Azteca instabilis; Coccus viridis; coffee agroforestry; mutualism; predatorprey interactions; self-organization; spatial pattern.

\section{INTRODUCTION}

Some of the earliest forays into ecology were concerned at least implicitly, with the spatial distribution of organisms (Turner 1989). Yet it was not until the 1990s that the study of spatially explicit models became popular (Dunning et al. 1995) and today it is one of the more vibrant growth areas of the discipline, effectively joining forces with the traditional field of landscape ecology (Tilman and Kareiva 1997, Turner et al. 2001). The study of space in ecology ranges from the description of movement of individuals from cell to cell in cellular automata models, to spatially explicit multispecies interactions at the local level described by Lotka-Voterra or Nicholson-Bailey models, to selforganization and the formation of large-scale spatial patterns in the distribution of organisms. A substantial body of ecological theory shows that (1) spatial pattern can spontaneously arise from the dynamic interactions among components in the system and (2) spatial pattern can determine the consequences of biological interactions. Thus, for example, local spread of a population coupled with regional control, the so-called Turing mechanism, can easily lead to a patchy spatial distribution (Turing 1952, Murray 1991). On the other hand, spatial heterogeneity per se is well known to be a potential stabilizing mechanism for biological interactions that are unstable at a local level (Steel 1974, May 1978, Tilman and Kareiva 1997).

Manuscript received 21 December 2006; accepted 6 February 2007; final version received 29 June 2007. Corresponding Editor: R. Greenberg. For reprints of this Special Feature, see footnote 1, p. 913 .

${ }^{3}$ E-mail: perfecto@umich.edu
Finding field data that speak to these theoretical ideas has been difficult (Rohani et al. 1997). Spatial patterns of populations in nature are most often observed in the context of habitat patterns, with patches of individuals associated with patches of habitat determined by abiotic or exogenous factors. Less common are cases in which a spatial pattern observed in nature can unequivocally be shown to be a consequence of biological interactions. One reason that such biologically determined spatial pattern is not often observed is that almost all habitats are patchy, thus automatically confounding the results of biological interactions with the patchiness of the environmental background.

Agroforestry systems, by design are almost always more uniform than natural systems. For this reason, they provide an excellent model system for studying the patterns of the distribution of organisms in space and the forces that generate them. Because of their underlying uniformity, they are ideal systems for studying three general areas in spatial ecology: (1) the quantitative evaluation of spatial pattern, (2) the mechanism of pattern generation, and (3) the consequences of spatial pattern. We treat each of these questions in turn, highlighting results from our own research in the coffee agroforestry system of Mesoamerica.

\section{The System}

In Mesoamerica, as well as other regions in Latin America, coffee is produced in an agroforestry system with shade trees interspersed with the coffee bushes that grow in the understory. Because the understory is uniformly planted with coffee and the canopy consists of a small number of species with a planted dominant 


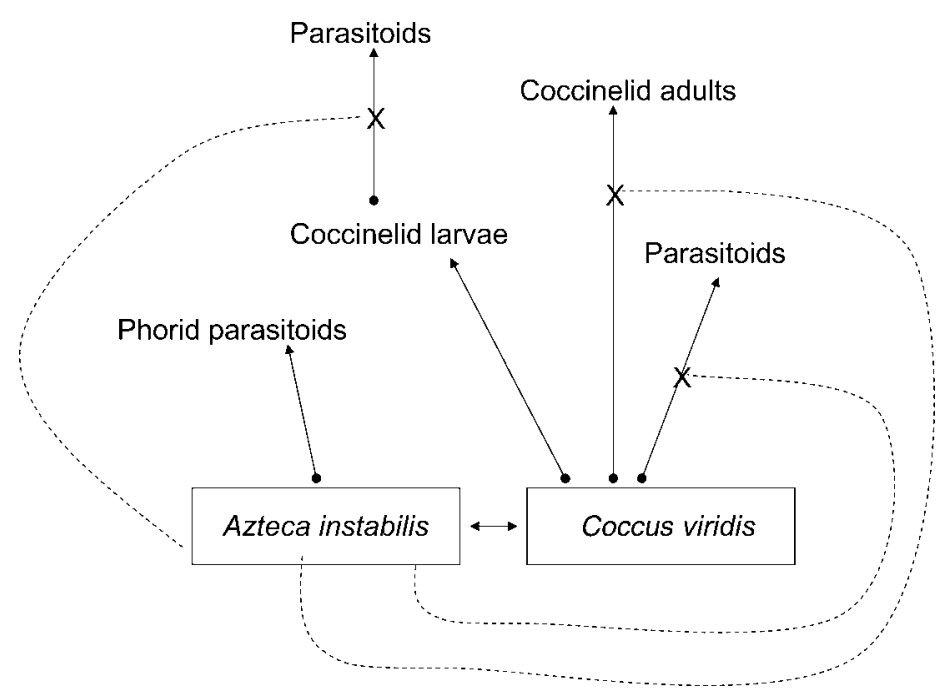

FIG. 1. Diagram of the Azteca system showing the ant-scale mutualism and the higher-level trophic interactions. The system consists of an arboreal ant ( $A$. instabilis), its scale insect mutualist (Coccus viridis), the natural enemies of the scale, the natural enemies of the enemies of the scale, and a phorid parasitoid of the ant. Arrows represent positive effects; solid circles represent negative effects; solid lines represent direct interactions; dashed lines represent indirect interactions; and the $x$ indicates an interaction that is affected by a third species (i.e., the arrows with solid circles represent predator-prey interactions and parasite-host interactions, and the double arrow represents a mutualistic interaction).

shade "backbone" of a single species or genus of evenaged trees, the coffee agroecosystem is spatially homogeneous relative to natural forest. Even so, this tropical managed system is highly diverse compared with other human managed systems (Perfecto et al. 1996, Moguel and Toledo 1999, Perfecto and Armbrecht 2003) and contains highly complex ecological interactions (Vandermeer et al. 2002, Armbrecht and Perfecto 2003, Armbrecht et al. 2004, 2005, Philpott et al. 2004a, $b$, 2005, Philpott 2005, Philpott and Armbrecht 2006). In this complex agroforestry system, we have identified a subsystem in which ecological interactions determine spatial pattern and that spatial pattern influences, even determines, key aspects of the ecological interactions.

The system consists of an arboreal ant, its scale insect mutualist, the natural enemies of the scale, the natural enemies of the enemies of the scale, and a phorid parasitoid of the ant (Fig. 1). The ant, Azteca instabilis, is an aggressive arboreal ant that nests in the shade trees. The trees with colonies are spatially aggregated (Vandermeer et al. 2008). The ant has a mutualistic relationship with Coccus viridis, a scale insect and an herbivore in coffee. Azteca protects $C$. viridis from its natural enemies and in turn harvests the honeydew that the scales produce. The natural enemies of $C$. viridis include the coccinelid beetle, Azya orbigera, and at least two parasitoids in the family Encyrtidae, however, the coccinelid beetle appears to be the main natural enemy in this system (H. Liere, unpublished data). Furthermore, the beetle larva, which is a voracious predator of the scale, is covered with waxy filaments that render it immune to the attack by the ants. Thus, clusters of trees with Azteca represent high quality patches for this myrmecophilic coccinelid larva since there is a high availability of food (scale insects) and indirect protection from predators and parasitoids by the harassment action of the ants (Liere and Perfecto, in press). A fly parasitoid (Pseudacteon sp., Phoridae) attacks the Azteca workers while they are foraging and tending scales, dramatically reducing their foraging activity (Philpott et al. 2004b, Philpott 2005). Finally, a fungal pathogen (Verticillium lecanii) attacks the scale insects, seemingly only when they reach a critical density, which only happens under the protection of ants.

\section{The Quantitative Evaluation of Spatial Pattern}

The earliest evaluations of spatial patterns focused on the simple question of whether a population had a random, uniform or aggregated distribution (Morisita 1959, Lloyd 1967), a focus that continues today only with far more sophisticated statistical analyses (Robertson 1987, Wackernagel 2003). However, questions of a more theoretical statistical nature have surfaced in recent years. Chief among them is the distribution of cluster sizes in a spatially patterned population (Pascual et al. 2002), noted in theoretical studies to frequently follow a power law (i.e., if $f[x]$ is the frequency of clusters of size $x$, then $f[x]=a x^{b}$ where $a$ and $b$ are constants).

Taking advantage of the highly replicated and spatially uniform distribution of coffee plants in the coffee agroecosystems, we examined the pattern of distribution of the scale insect, $C$. viridis associated with individual coffee bushes in the relatively homogeneous sea of coffee found in the understory. In particular, we examined how this pattern might vary in the presence or absence of Azteca, the key mutualist of the scale. Estimating population densities on over 600 coffee bushes, we observed that the spatial pattern did, indeed, reflect an underlying power law (Vandermeer and Perfecto 2006a), with significant deviations at large cluster sizes (those encountered in Azteca patches [Vandermeer and Perfecto 2006a]), and with systematic deviations also at smaller cluster sizes. Scale insect distribution provides an example of a spatial distribution governed by simple biological rules associated with birth, death, and immigration rates within subpopulations (Alonso and Pascual 2006). Kendall (1948) long 
ago noted that depending upon these rates, the statistical distribution of subpopulations would follow either Fisher's log series distribution or a negative binomial. Alonso and Pascual (2006) found a close fit to the negative binomial, thus explaining what we had characterized only as deviations from a power series, and also reinforced the conclusion that high density deviation from the power law was a consequence of the ant mutualism. Thus we see an overall pattern in which a metapopulation is an example of Kendall's hypothesis in which the lognormal, negative binomial, and logseries can be seen as part of the same general theory, the lognormal being the expected final state when subpopulations have positive growth rates, but either the negative binomial or logseries when subpopulations have negative growth rates with the entire metapopulation maintained by the migration coefficients (Vandermeer and Perfecto 2006b).

\section{The Mechanism of Pattern Generation}

Distinguishing between the importance of intrinsic (density-dependent) and extrinsic (density-independent) factors in governing population processes has a long history in ecology (May 1984, Borcard et al. 1992, Legendre 1993). A similar dichotomy has emerged in the study of spatial pattern, usually referred to as selforganized (intrinsic) or not (Hassell et al. 1994, Rohani et al. 1997, Reitkerk et al. 2004). A large theoretical literature demonstrates that a variety of intrinsic arrangements can give rise to complex, and sometimes beautiful, spatial patterns (Czárán and Bartha 1992, Wilson et al. 1993, Gurney and Veitch 2000, Camazine et al. 2003). However, spatial patterns of populations in nature are often attributed to underlying habitat patterns, with patches of individuals associated with patches of habitat, which, in turn, are determined by extrinsic factors such as type of soils, humidity, and so on. Spatial pattern in nature that can be shown to be a consequence of biological interactions (e.g., Maron and Harrison 1997, Wootton 2001, Reitkerk et al. 2004), are far less common, even though many theoretical formulations suggest this should frequently be the case (Rohani et al. 1997).

Here again, the coffee agroforestry system offers an excellent opportunity to empirically distinguish between these two alternatives, because of the underlying habitat uniformity. Since in this system, Azteca nests occurred in some sort of non-uniform pattern, we tested the hypothesis of self-organization (Vandermeer et al. 2008).

A map of all $A$. instabilis nests on a 45 -ha plot shows a clear clumped pattern (Fig. 2A), providing initial support for the hypothesis of intrinsic control of spatial pattern (Vandermeer et al. 2008). While it is conceivable that some underlying habitat variable (tree species or size, for example) provides an extrinsic forcing to create the pattern, we found no evidence for that (Vandermeer et al. 2008; I. Perfecto and J. Vandermeer, unpublished data). It is not completely clear what intrinsic forces are
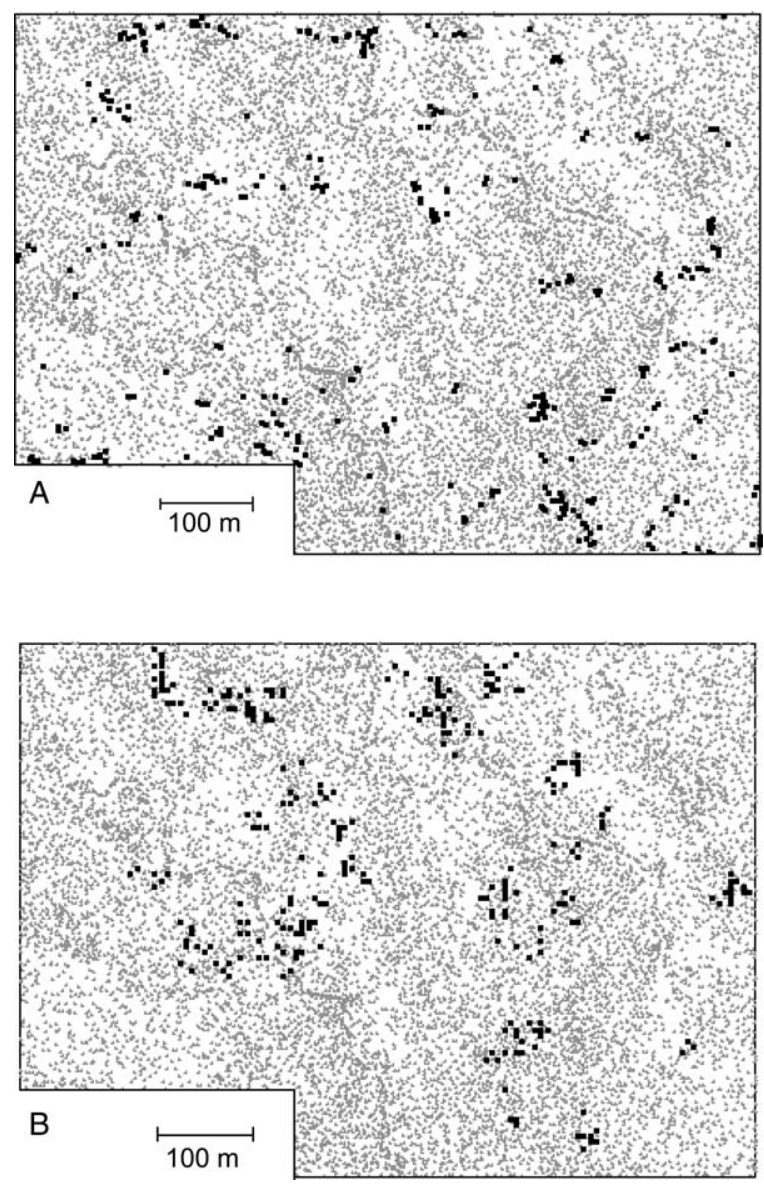

FIG. 2. (A) Map of the 45-ha plot in a coffee plantation showing all trees $>10 \mathrm{~cm}$ circumference (in gray) and all trees that contain an Azteca instabilis nest (black) as of August 2005. (B) An example model simulation plotted on a background of the actual distribution of trees in the natural plot, for parameter settings $m_{0}=0.13$ and $m_{1}=0.036$ (parameters of phorid attack), and $s_{0}=0.0035$ and $s_{1}=0.035$ (parameters of satellite nest expansion). The simulation is based on a $120 \times 90$ lattice; $N=$ 261 , mean variance ratio $=0.43$.

involved. However, based on the natural history and ancillary studies of the species, we hypothesize that Azteca clumps are formed by the local establishment of satellite colonies, followed by control from a natural enemy that responds to local population density (Vandermeer et al. 2008). Thus, local clusters are formed by the process of local satellite nest expansion, but then a density responsive natural enemy is especially effective at high local densities, the basic idea of the Turing mechanism of pattern formation in which local activation is balanced by regional repression (Ellner and Guckenheimer 2006).

Formulating a simple stochastic cellular automata model based on local activation and regional repression, we were able to reproduce the qualitative features of the spatial distribution of the ant colonies (Fig. 2B), within the range of parameters estimated from five field surveys of the ants. The precise parameter estimates did not, in 
fact, reproduce the pattern observed. However, we found a set of parameter values that fell within the range determined by the extreme estimates of all parameters that gave a qualitatively similar pattern to the one we observed in nature (Vandermeer et al. 2008).

\section{The Consequences of Spatial Pattern}

The theoretical literature on the effects of space on biological interactions is large (Tilman and Kareiva 1997). Of particular interest is the situation in which the nature of local biological interactions can be altered when casting the problem spatially. Perhaps the simplest example is that of source-sink dynamics. A complication that is not often acknowledged is when the patchiness that permits source/sink dynamics is itself generated by intrinsic biological properties. An excellent example of this occurs in the coffee agroforestry system in which Azteca forms clusters and acts as a predator within those clusters.

For example, the most important current insect pest in coffee in Mesoamerica is the coffee berry borer (Hypothenemus hampei), a small scolitid beetle that burrows into the ripening coffee fruit, causing considerable economic damage (Damon 2000). It is now well established that ants can be important predators of this pest (Philpott and Armbrecht 2006). In the case of spatial patchiness, we have a clear example of a possible sink (within patches of the predator ant) and a source (the rest of the coffee farm). Because Azteca tends scale insects, some farmers consider it a pest in coffee. Yet, Azteca also creates sink habitats for the borer (Perfecto and Vandermeer 2006), which clearly represent a sort of spatially induced biological control (Vandermeer et al. 2002). Thus this example of potential "control from above" can be fully understood only if the biological interactions (mutualism, herbivory and predation) are cast in their spatially explicit framework.

A more complicated case involves the coccinelid beetle $A$. orbigera, a voracious predator of the scale insects. As mentioned earlier, the larva of this beetle is protected from the harassment activity of the ants, while the adults are not. Furthermore, the ant incidentally harasses the natural enemies of the beetle larvae, inadvertently protecting the larvae much as it protects the scale insect mutualists (Liere and Perfecto, in press). Thus, the extended spatial system confronts a situation in which there are patches (those with ants) in which the adult coccinelids are virtually excluded from eating but the larvae is protected from natural enemies and has ample food resources, and other patches (the areas without ants) in which scale density is very low and the coccinelid larvae probably are unable to survive. Given these conditions, it is not difficult to imagine a twopatch situation in which the predator/prey system is unstable (or non persistent) in both patches: in one patch the adult beetle is unable to feed, while in the other patch the larvae cannot find enough food to sustain itself. A collection of such patches, if isolated from one another would obviously result in the elimination of the predator from the system. However, linking the two patches together by means of interpatch migration could result in persistence over the whole space. The idea is effectively a metapopulation with two patch types where the population is expected to go extinct in each of the patches, but each patch is continually "rescued" (Gotelli 1991) from permanent extinction by migration from the other patch.

Circumstantial evidence exists that the beetle $A$. orbigera and its prey, $C$. viridis, the scale insect, exist in just such a situation in the coffee agroecosystem $(\mathrm{H}$. Liere, unpublished data). In the absence of Azteca, the beetle larvae are attacked at a high rate by at least three species of parasitic wasps, rendering their effective intrinsic rate of mortality extremely high. Add to this the fact that in the absence of ants the scale insects, which are their main prey, have extremely low population densities. In the presence of Azteca, the abundance of the prey ( $C$. viridis) is high due to protection provided by the ants, and the beetle larvae are indirectly protected from their natural enemies by the ants, such that the ants effectively enrich the environment of the beetle predator. It thus appears that the beetle exists in two environments, both of which would normally lead to its extinction.

Adult beetles must migrate between patches with and without Azteca in order to maximize the tradeoff between egg laying and feeding. To increase larval survival the adults must place their offspring in habitats with abundant food and under the protection of the ants. Yet adults cannot feed in Azteca patches because of harassment from ants, and must migrate to patches without Azteca in order to feed. Migration from patch to patch thus appears to stabilize this inherently unstable situation (H. Liere et al., unpublished data).

Another host-parasitoid system that seems to be stabilized when spatially extended is the Azteca-Pseudacteon system mentioned earlier. The theoretical literature identifies two potential stabilization mechanisms that have to do with the response of the parasitoid to spatial pattern. One of them is a behavioral response that occurs at a very local level (Murdoch and StewartOaten 1989) and the other is a demographic response that occurs at a much larger spatial scale with heterogeneous patches of host concentrations (Hassell et al. 1994, Maron and Harrison 1997, Wootton 2001). In the coffee agroforestry system, where the habitat is divided into Azteca patches and patches without Azteca we find that Pseudacteon attacks vary with distance from Azteca colony within a patch and are significantly higher in Azteca patches than in patches without Azteca (Vandermeer et al. 2008). What is particularly interesting of this system is that the spatial heterogeneity is hypothesized to be caused, at least in part, by the phorid fly through the Turing mechanism. Thus we have a situation where a host-parasite system may be stabilized 
because of the spatial heterogeneity that it, itself, is partially responsible for creating.

\section{CONCLusion}

The coffee agroforestry system has proven useful for the study of spatial ecology. The uniform pattern of the coffee plants and shade trees has allowed researchers to search for spatial patterns generated through biological interactions. In particular the detailed studies we have conducted in a 45-ha plot in a coffee agroforestry system have provided insights into the quantitative evaluation of spatial patterns, the mechanisms for the generation of patterns, and the consequences of the spatial pattern for the stability of predator-prey (host-parasitoid) systems. Thus far, three main insights into spatial ecology have been elucidated by studying the coffee agroforestry system. (1) Metapopulations can be conceived as Kendall's birth, death, immigration process, leading to the overall interpretation that the lognormal, negative binomial, and logseries distributions can be seen as part of the same general theory (Vandermeer and Perfecto $2006 a, b)$. (2) Spatial pattern may form in a homogenous background as a result of intrinsic factors operative at a large scale. More specifically, clusters of Azteca ants are self-organized, mediated by satellite colony expansion followed by a natural control agent, and show a densitydependent response (Vandermeer et al. 2008). (3) The spatial heterogeneity generated by these intrinsic factors may lead to the stabilization of host/parasite systems. As an example, the scale-coccinelid system, which is unstable within each habitat patch (with and without Azteca) in isolation, is stabilized when these two types of patches are connected (H. Liere, unpublished data). Further, the Azteca-Pseudacteon system, appears to be stabilized due to a demographic response in an heterogeneous landscape that causes the phorids to have higher attack rates in Azteca patches than in patches without Azteca (Vandermeer et al. 2008).

Traditionally, ecologists have avoided working in managed ecosystems because of the inherent human manipulation to which they are subjected and the somewhat artificial nature of the systems. Ironically, it is precisely because of these attributes that the coffee agroforestry system has yielded some novel insights in spatial ecology.

\section{ACKNOWLEDGMENTS}

The research described in this article is the result of a collective effort between us (I. Perfecto and J. Vandermeer) and our graduate students and colleagues at the University of Michigan and the Colegio de la Frontera Sur-Tapachula. In particular, we acknowledge H. Liere, S. Uno, S. Philpott, and D. Jackson. J. Maldonado, B. Estaban Chilel, and G. LópezBautista performed the bulk of the field censuses. We thank the Peters Foundation for permission to establish the plot on Finca Irlanda, and for considerable logistic support. El Colegio de la Frontera Sur (ECOSUR), and especially G. Ibarra Núñez and A. Garcia-Ballinas provided critical logistical support. This work was supported by an NSF grant DEB 0349388 to I. Perfecto and $\mathbf{J}$. Vandermeer.

\section{Literature Cited}

Alonso, D., and M. Pascual. 2006. Comment of "A keystone mutualism drives patterns in a power function." Science 313: 1739.

Armbrecht, I., and I. Perfecto. 2003. Litter ant's diversity and predation potential in two Mexican coffee matrices and forest fragments. Agriculture, Ecosystems and Environment 97: 107-115.

Armbrecht, I., I. Perfecto, and J. Vandermeer. 2004. Enigmatic biodiversity correlations: ant diversity responds to diverse resources. Science 304:284-286.

Armbrecht, I., L. Rivera, and I. Perfecto. 2005. Reduced diversity and complexity in the leaf litter ant assemblage of Colombian coffee plantations. Conservation Biology 19:897907.

Borcard, D., P. Legendre, and P. Drapeau. 1992. Partialling out the spatial component of ecological variation. Ecology 73: 1045-1055.

Camazine, S., J. L. Deneubourg, N. R. Franks, J. Snayd, G. Theraulaz, and E. Bonabeau. 2003. Self-organization in biological systems. Princeton University Press, Princeton, New Jersey, USA.

Czárán, T., and S. Bartha. 1992. Spatiotemporal dynamic models of plant populations and communities. Trends in Ecology and Evolution 7:38-42.

Damon, A. 2000. A review of the biology and control of the coffee berry borer, Hypothenemus hampei (Coleoptera: Scolytidae). Bulletin of Entomological Research 90:453-465.

Dunning, J. B., Jr., D. J. Stewart, B. J. Danielson, B. R. Noon, T. L. Root, and E. E. Stevens. 1995. Spatially explicit population models: current forms and future uses. Ecological Applications 5:3-11.

Ellner, S. P., and J. Guckenheimer. 2006. Dynamic models in biology. Princeton University Press, Princeton, New Jersey, USA.

Gotelli, N. J. 1991. Metapopulation models: the rescue effect, the propagule rain, and the core-satellite hypothesis. American Naturalist 138:768-776.

Gurney, W. S. C., and A. R. Veitch. 2000. Self-organization, scale and stability in a spatial predator-prey interaction. Bulletin of Mathematical Biology 62:61-86.

Hassell, M. P., H. N. Comins, and R. M. May. 1994. Species coexistence and self-organizing spatial dynamics. Nature 370: 290-292.

Kendall, D. G. 1948. On the generalized "birth-and-death" process. Annals of Mathematical Statistics 19:1-15.

Legendre, P. 1993. Spatial autocorrelation-trouble or new paradigm. Ecology 74:1659-1673.

Liere, H., and I. Perfecto. In press. Cheating in a mutualism: indirect benefits of ant attendance to a coccidophagous coccinelid. Ecological Entomology.

Lloyd, M. 1967. Mean crowding. Journal of Animal Ecology 36:1-30.

Maron, J. L., and S. Harrison. 1997. Spatial pattern formation in an insect host-parasitoid system. Science 278:1619-1621.

May, R. 1978. Host-parasitoid systems in patchy environments: a phenomenological model. Journal of Animal Ecology 47: 833-843.

May, R. 1984. An overview: real and apparent patterns in community structure. Pages $3-16$ in D. R. Strong, D. Simberloff, L. G. Abele, and A. B. Thistle, editors. Ecological communities: conceptual issues and the evidence. Princeton University Press, Princeton, New Jersey, USA.

Moguel, P., and V. M. Toledo. 1999. Biodiversity conservation in traditional coffee systems of Mexico. Conservation Biology 13:11-21.

Morisita, M. 1959. Measuring the dispersion of individuals and analysis of the distributional patterns. Memoirs of the Faculty of Science, Kyushu University, Series E: 3:65-80. 
Murdoch, W. W., and A. Stewart-Oaten. 1989. Aggregation by parasitoids and predators: effects on equilibrium and stability. American Naturalist 134:288-310.

Murray, J. D. 1991. Mathematical biology. Springer, Berlin, Germany.

Pascual, M., M. Roy, F. Guichard, and G. Flierl. 2002. Cluster size distributions: signature of self-organization in spatial ecologies. Philosophical Transactions of the Royal Society B 1421:657-666.

Perfecto, I., and I. Armbrecht. 2003. The coffee agroecosystem in the Neotropics: combining ecological and economic goals. Pages 159-194 in J. H. Vandermeer, editor. Tropical agroecosystems. CRC Press, Boca Raton, Florida, USA.

Perfecto, I., R. Rice, R. Greenberg, and M. Van der Voolt. 1996. Shade coffee as refuge of biodiversity. BioScience 46: 589-608.

Perfecto, I., and J. Vandermeer. 2006. The effect of an anthemipteran mutualism on the coffee berry borer (Hypothenemus hampei) in southern Mexico. Agriculture, Ecosystems and Environment 117:218-221.

Philpott, S. M. 2005. Trait-mediated effects of parasitic phorid flies (Diptera: Phoridae) on ant (Hymenoptera: Formicidae) competition and resource access in coffee agro-ecosystems. Environmental Entomology 34:1089-1094.

Philpott, S. M., and I. Armbrecht. 2006. Biodiversity in tropical agroforests and the ecological role of ants and ant diversity in predatory function. Ecological Entomology 31:369-377.

Philpott, S. M., R. Greenberg, P. Bichier, and I. Perfecto. $2004 a$. Impacts of major predators on tropical agroforest arthropods: comparisons across taxa. Oecologia 140:140149.

Philpott, S. M., J. Maldonado, J. Vandermeer, and I. Perfecto. 2004b. Taking trophic cascades up a level: behaviorallymodified effects of phorid flies on ants and ant prey in coffee agroecosystems. Oikos 105:141-147.

Reitkerk, M., S. C. Dekker, P. C. de Ruiter, and J. van de Koppel. 2004. Self-organized patchiness and catastrophic shifts in ecosystems. Science 305:1926-1929.

Robertson, G. P. 1987. Geostatistics in ecology: interpolating with known variance. Ecology 68:744-748.
Rohani, P., T. J. Lewis, D. Grünbaum, and G. D. Ruxton. 1997. Spatial self-organization in ecology: pretty patterns or robust reality? Trends in Ecology and Evolution 12:70-74.

Steel, J. H. 1974. Spatial heterogeneity and population stability. Nature 248:83.

Tilman, D., and P. Kareiva. 1997. Spatial ecology: the role of space in population dynamics and interspecific interactions. Princeton University Press, Princeton, New Jersey, USA.

Turing, A. 1952. The chemical basis of morphogenesis. Philosophical Transactions of the Royal Society of London B 237:37-72.

Turner, M. G. 1989. Landscape ecology: the effect of pattern and process. Annual Review of Ecology and Systematics 20: 171-97.

Turner, M. G., R. H. Gardner, and R. V. O’Neill. 2001. Landscape ecology in theory and practice: pattern and process. Springer-Verlag, New York, New York, USA.

Vandermeer, J., and I. Perfecto. 2006a. A keystone mutualism drives pattern in a power function. Science 311:1000-1002.

Vandermeer, J., and I. Perfecto. 2006b. Response to comments on "A keystone mutualism drives patterns in a power function." Science 313:1739.

Vandermeer, J., I. Perfecto, G. Ibarra Nuñez, S. Philpott, and A. Garcia Ballinas. 2002. Ants (Azteca sp.) as potential biological control agents in shade coffee production in Chiapas, Mexico. Agroforestry Systems 56:271-276.

Vandermeer, J., I. Perfecto, and S. M. Philpott. 2008. Clusters of ant colonies and robust criticality in a tropical agroecosystem. Nature 451:457-459.

Wackernagel, H. 2003. Multivariate geostatistics: an introduction with applications. Springer, Berlin, Germany.

Wilson, W. G., A. M. deRoos, and E. McCauley. 1993. Spatial instabilities within the diffusive Lotka-Volterra system: individual-based simulation results. Theoretical Population Biology 43:91-127.

Wootton, J. T. 2001. Local interactions predict large-scale pattern in empirically derived cellular automata. Nature 413: 841-844. 